\title{
Status and conservation of the Endangered snow leopard Panthera uncia in Qomolangma National Nature Reserve, Tibet-CORRIGENDUM
}

Pengue Chen, Yufang Gao, Jun Wang, Qiong Pu, Cering Lhaba, Huijan Hu JiAN XU and KUN SHI

DOI:10.1017/S0030605316000284. Published online by Cambridge University Press, 7 July 2016

On p. 2 of Chen et al. (2016) the sentence 'The gross domestic product increased at an annual growth rate of $15 \%$, from $\mathrm{CNY}$ 2.59 billion in 2000 to CNY 18.51 billion in 2014 ' should read 'The gross domestic product increased at an annual growth rate of $15 \%$, from CNY 0.26 billion in 2000 to CNY 1.85 billion in 2014.' Fig. 2 has been corrected to reflect this change.

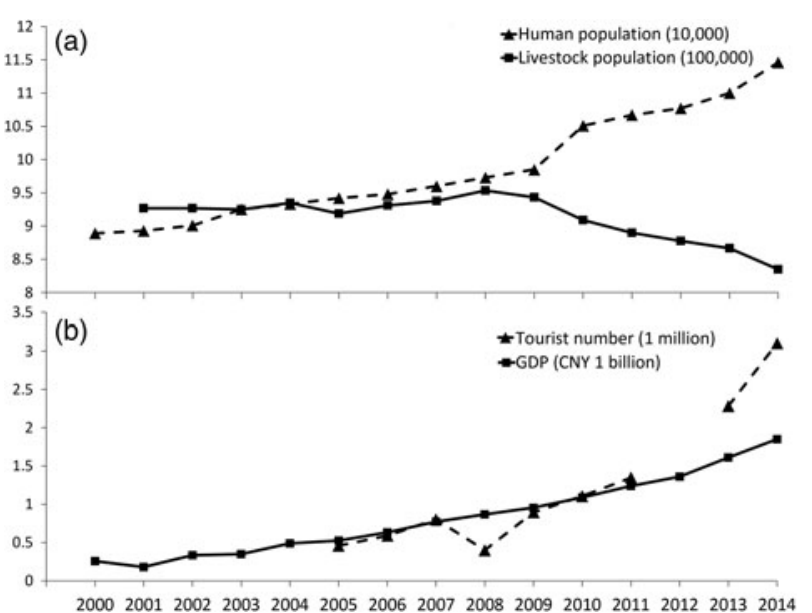

200020012002200320042005200620072008200920102011201220132014

\section{Reference}

Chen, P., Gao, Y., Wang, J., Pu, Q., Lhaba, C., Hu, H. et al. Status and conservation of the Endangered snow leopard Panthera uncia in Qomolangma National Nature Reserve, Tibet. Published 7 July 2016, doi:10.1017/Soo30605316000284. 